\title{
Frequency of HLA Antigens in a Sample of Iraqi Brucellosis Patients
}

\author{
Ali H. Ad'hiah* \\ Ammna N. Jasim**** \\ Aaiad H. A. Al-Rikaby** \\ Received 30, May, 2010 \\ Accepted 11, October, 2010
}

\begin{abstract}
:
Fifty one patients with serologically confirmed brucellosis and 70 healthy controls were phenotyped for HLA-A, -B, -DR and -DQ antigens by using standard microlympho-cytotoxicity method, and lymphocytes defined by their $\mathrm{CD}$ markers $(\mathrm{CD} 3, \mathrm{CD} 4, \mathrm{CD} 8$ and $\mathrm{CD} 19)$. The results revealed a significant $(\mathrm{Pc}=0.001)$ increased frequency of HLA-DR8 (41.18 vs. 10.0\%) in the patients . A significant increased percentage of CD8+ lymphocytes was also increased in the patients $(25.15$ vs. 22.0\%; $\mathrm{P}=0.006)$, while $\mathrm{CD} 3+$ lymphocytes were significantly decreased (75.1 vs. $79.4 \% ; \mathrm{P}=0.02)$.
\end{abstract}

Key words: Brucellosis, HLA, CD markers.

\section{Introduction:}

Brucellosis is the most common zoonotic disease with worldwide distribution, and more than 500000 new cases are reported annually. It is caused by intracellular pathogens of the genus Brucella that have their natural reservoir in domestic and wild animals. The disease is transmitted to humans by consumption of contaminated dairy products or by occupational contact with infected animals [1]. The genus Brucella consist of seven species according to antigenic variation and primary host: B. melitensis (sheep and goats), B. suis (hogs), B. abortus (cattle), B. ovis (sheep), B. canis (dogs), B. neotomae (wood rats) and $B$. maris (marine mammals) [2].

Brucella infection occurs through inhalation or ingestion of organisms via the nasal, oral, or pharyngeal cavities, and following penetration of the mucosal epithelium, the bacteria are transported, either free or within phagocytic cells, to the regional lymph nodes [3]. The spread and multiplication of Brucella in lymph nodes, spleen, liver, bone marrow, mammary glands, and sex organs occurs via macrophages. In general, B. melitensis, B. abortus and $B$. suis can infect humans and the pathological manifestations of brucellosis in humans are meningitis, endocarditis, spondylitis, and arthritis [4].

Cellular immune responses are a critical part of the host defense against intracellular bacterial infections, but the response against Brucellae spp. involves the whole principles of the immune system from innate to adaptive immunity. In brucellosis, the different arms of the immune system, namely antigen-presenting cells, natural killer (NK) cells, CD4+ and CD8+ T cells and B cells, act together to provide a coordinated response [5]. The primary mechanism of control involves cell-mediated immunity rather than antibodies, although some immunity against re-infection is provided by serum immunoglobulins

*Tropical-Biological Research Unit, College of Science, University of Baghdad.

**Department of Biology, College of Education Ibin Al-Haitham, University of Baghdad.

***Department of Biology, College of Science for Women, University of Baghdad. 
[6]. However, the immunological recognition of non-self antigens; viral, bacterial or parasitic, is dependent on self antigens, which are collectively known as human leukocyte antigens (HLA). These antigens are genetically controlled, and their expression shows an extensive polymorphism, and certain HLA alleles have shown positive associations with different diseases; including autoimmune, viral, bacterial and parasitic diseases [7], and human brucellosis is one of these diseases that has been studied in relation to HLA antigens $[8,9,10]$.

Accordingly the present investigation aimed to investigate the association between HLA-class I (A and $\mathrm{B}$ ) and class II (DR and DQ) antigens and brucellosis in a sample of Iraqi patients. The profile of lymphocytes (CD3+, CD4+, CD8+ and CD19+ cells) were also investigated.

\section{Materials and Methods:}

Blood samples $(10 \mathrm{ml})$ were collected from 51 brucellosis patients (25 males and 26 females), who were administrated to the Al-Karama Teaching Hospital, and their age range at the time of diagnosis was 17-50 years. The diagnosis was made by the consultant medical staff, and based on a clinical examination and laboratory investigations, which included RoseBengal test and indirect immunofluorescence antibody test (IFAT). A control sample of 70 apparently healthy subjects (blood and kidney donors) was also included, and they were age, sex and ethnicity (Arab Muslims) matched.

The blood was drawn in a hepranized tube and lymphocytes were isolated by means of a density gradient centrifugation using lymphoprep as a separating medium. These lymphocytes were further separated into $\mathrm{T}$ - and B-cells using the nylonwool method. The $\mathrm{T}$ lymphocytes were

employed in the phenotyping of HLAclass I antigens (A and $B$ ), while $B$ lymphocytes were used in the phenotyping of HLA class II antigens (DR and DQ). The microlymphocytotoxicity test was applied to determine these phenotypes using commercially available antisera (Biotest, Germany) that recognized 8 A, 14 B, 8 DR and 2 DQ antigens [11]. The total lymphocytes were also characterized in terms of their CD profiles (CD3+, CD4+, CD8+ and CD19+ cells), which were investigated using a commercially available monoclonal antibodies against each CD marker (Serotec, France). The method of detection was direct immunofluorescence as suggested by the kit's manufacturer.

The data of HLA were presented as observed numbers and percentage frequencies, and antigens showing significant variation (Fisher's exact probability; P) were further presented as odd ratio (OR), etiological fraction (EF) and preventive fraction (PF). The probability was corrected for the number of antigen tested at each locus [11]. The statistical analysis of these presentations was carried out using the computer programme PEPI version 4. The data of CD profile were given as means \pm standard errors (S.E.), and significant differences between means were assessed by the least significant difference (LSD) using the computer programme SPSS version 15.

\section{Results:}

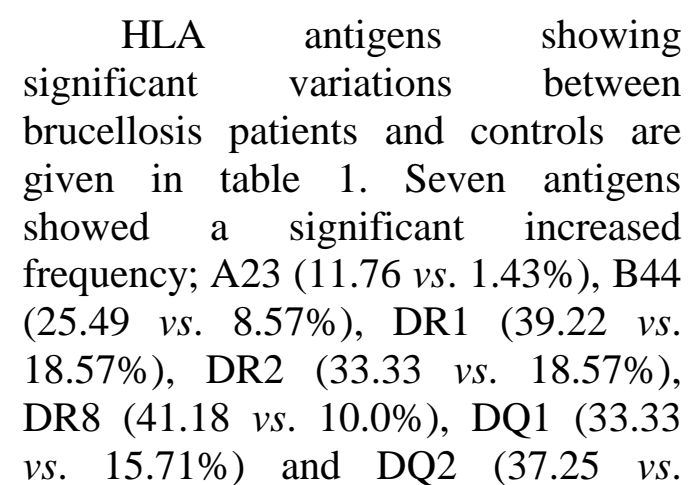


20.0\%), while three antigens showed a significant decreased frequency; A11 (5.89 vs. $18.57 \%)$, A32 (0.0 vs. $11.43 \%)$ and B35 (7.84 vs. 20.0) in the patients as compared to controls. Correcting the $\mathrm{P}$ values of these variations revealed that only the increased frequency of DR8 maintained a significant corrected level $(\mathrm{Pc}=0.001)$, moreover, such variation was associated with an OD value of 6.30 and $\mathrm{EF}$ value of 0.34 .

The CD profile of lymphocytes revealed that $\mathrm{CD} 3+$ cells showed a significant decreased percentage (75.1 vs. $79.4 \% ; \mathrm{P}=0.02$ ), while CD8+ cells showed a significant increased percentage $(25.15$ vs. $22.0 \%$; $\mathrm{P}=$ 0.006) in the patients as compared to controls. The CD4+ lymphocytes were also decreased in the patients $(38.95$ vs. 39.55\%), but the difference did not attained a significant level $(\mathrm{P}>0.05)$. Whereas the CD4/CD8 ratio maintained a significant decrease (1.58 vs. $1.82 ; \mathrm{P}=0.003)$ in the patients. The CD19+ cells showed a non-significant increase in the patients (19.35 vs. $18.70 \%$ ) (Table 2).

\section{Discussion:}

Infectious diseases are a major selective pressure, and the genes involved in the immune response are the most numerous and diverse in the human genome, indicating the evolutionary advantages of a varied immunological response to a wide range of infectious pathogens. This is most obvious at the HLA loci, the prototypical candidate genetic region for infectious disease susceptibility [12]. The present results demonstrated that brucellosis was associated with abnormalities in the percentage of CD3+, which are pan T-lymphocytes, and CD8+, which are T-cytotoxic. The latter cells are involved in cellmediated immunity, which is the responsible immunity against Brucella infection, although humoral immunity might have a role [5,6]. However, both immunities are MHC-restricted, and the HLA antigens may have an effect as they are the recognition molecules [13]. Comparing the patients and controls revealed that HLA-DR8 was significantly increased in the patients, and such deviation was associated with an OR value of 6.30 and $\mathrm{EF}$ value of 0.34 . Such positive association may highlight the importance of such antigen as a predisposing immunogenetic marker conferring about $34 \%$ predisposition. Additionally, CD8+ lymphocytes were also significantly increased in the patients. Therefore, part of the genetic susceptibility to brucellosis may be attributed to polymorphisms in the HLA region genes. These genes encode for the cell-surface human HLA class I (HLA-A, -B, and -C) and class II (HLA-DR, -DQ, and -DP) molecules, which play an important role in the regulation of the immune system. Most nucleated cells express HLA class I genes, whereas expression of HLA class II genes is restricted to specialized antigen-presenting cells. HLA class I and class II molecules present antigenic peptides to $\mathrm{CD} 8+$ and CD4+ $\mathrm{T}$ cells, respectively [7]. The variability observed among these molecules, HLA-DR8 antigen in the present investigation, is located in the peptide-binding region, which is important in determining the antigen repertoire that is displayed to $\mathrm{T}$ cells by each HLA molecule. The interaction between the HLA-peptide complex and the $\mathrm{T}$ cell receptor is an essential and specific step in $\mathrm{T}$ cell activation [14]. In this regard, it has been demonstrated by using immunofluorescence that lipopolysaccharide (LPS), a major amphiphilic molecule located at the outer membrane of Brucella, is able to accumulate in an intracellular 
compartment enriched in MHC class II molecules, and by the use of immunoprecipitation, it was illustrated that Brucella abortus LPS is associated with MHC class II molecules in a haplotype-independent manner. Taken together, these results raised the possibility that $B$. abortus LPS may play a role in T-cell activation, which is dependent on the MHC class II molecule [15].

Regarding HLA polymorphisms and the risk of brucellosis, discordant results have been observed among different populations or even in the same population. For instance, an earlier study in Spanish patients recorded a significant decreased frequency of HLA-Cw2 [16], while a later study reported a significant increased frequency of HLA-B39, especially in patients who had osteoarticular complications [8], but both investigations showed no association with HLA-B27. These three antigens showed no significant variations between the present brucellosis patients and controls. The latter antigen (HLA-B27) shared most of the controversy in relation to brucellosis especially in patients who had osteoarticular complications and arthritis, and the studies either reported a significant increase $[9,10]$, or no association was recorded [16], including Iraqi patients [17].

With respect to lymphocyte phenotypes, the most significant findings were decreased percentage of CD3+ cells and increased percentage of CD8+ cells, while CD4+ lymphocytes showed a non-significant decrease. The significance of CD4+ and/or CD8+ $\mathrm{T}$ cells in Brucella immunity has been controversial. Araya et al. [18] reported that both Tcell populations are important. However, Oliveira and Splitter [19] reported that major MHC class Ideficient mice, which have no $\mathrm{CD} 8+\mathrm{T}$ cells, control the infection more slowly than do wild-type mice, while MHC class II deficient mice, defective in CD4+ T cells, control the infection at a similar rate to wild-type mice. These results suggest that $\mathrm{CD} 8+\mathrm{T}$ cells play a critical role although the role of CD4+ T cells in brucellosis should not be ignored. Moreno-Lafont et al. [20] reported an increase in the percentage of CD8+ T-cells in the peripheral blood of patients chronically infected with Brucella spp. In addition, they found increased numbers of Brucella antigen-specific CD8+ T cells. Gazapo et al. [21] observed both a decreased percentage of CD4+ lymphocytes and an increase in $\mathrm{CD} 8+$, hence an inverted CD4+/CD8+ ratio that was also observed in the present study, at the time of diagnosis.

In conclusion, the HLA profile in brucellosis patients may be subjected to race variations, because HLA antigens show different frequencies in different populations [22], but in each population there may be a single antigen that is able to predispose the individual to develop brucellosis in interaction with the strain that cause the infection, and such interaction involves CD8+ T lymphocytes. 
Table 1: HLA antigens showing significant variations between brucellosis patients and controls.

\begin{tabular}{|c|c|c|c|c|c|c|c|c|}
\hline \multirow{2}{*}{$\begin{array}{c}\text { HLA } \\
\text { Antigens }\end{array}$} & \multicolumn{2}{|c|}{ Patients(No. $=51)$} & \multicolumn{2}{|c|}{ Controls(No. $=70$ ) } & \multirow{2}{*}{$\begin{array}{l}\text { Odd } \\
\text { Ratio }\end{array}$} & \multirow{2}{*}{ EF or PF } & \multirow{2}{*}{$\mathrm{P}$} & \multirow{2}{*}{$\mathrm{Pc}$} \\
\hline & No. & $\%$ & No. & $\%$ & & & & \\
\hline A11 & 3 & 5.89 & 13 & 18.57 & 0.27 & 0.14 & 0.04 & N.S. \\
\hline A23 & 6 & 11.76 & 1 & 1.43 & 9.20 & 0.11 & 0.02 & N.S. \\
\hline A32 & ND & ND & 8 & 11.43 & - & - & 0.01 & N.S. \\
\hline B35 & 4 & 7.84 & 14 & 20.00 & 0.34 & 0.11 & 0.05 & N.S. \\
\hline B44 & 13 & 25.49 & 6 & 8.57 & 3.64 & 0.18 & 0.01 & N.S. \\
\hline DR1 & 20 & 39.22 & 13 & 18.57 & 2.83 & 0.25 & 0.01 & N.S. \\
\hline DR2 & 17 & 33.33 & 13 & 18.57 & 2.19 & 0.18 & 0.05 & N.S. \\
\hline DR8 & 21 & 41.18 & 7 & 10.00 & 6.30 & 0.34 & 0.0001 & 0.001 \\
\hline DQ1 & 17 & 33.33 & 11 & 15.71 & 2.68 & 0.21 & 0.02 & N.S. \\
\hline DQ2 & 19 & 37.25 & 14 & 20.00 & 2.38 & 0.21 & 0.03 & N.S. \\
\hline
\end{tabular}

EF: Etiological fraction; PF: Preventive fraction; P: Probability; Pc: Corrected P; ND: Not detected.

Table 2: Percentage of lymphocyte phenotypes in the peripheral blood of brucellosis patients and controls.

\begin{tabular}{|c|c|c|c|}
\hline \multirow{2}{*}{ Lymphocytes } & \multicolumn{2}{|c|}{ Mean \pm S.E. (\%) } & \multirow{2}{*}{ Probability } \\
\cline { 2 - 3 } & $\begin{array}{c}\text { Patients (No.= } \\
20 \text { ) }\end{array}$ & $\begin{array}{c}\text { Controls(No.= } \\
20)\end{array}$ & 0.02 \\
\hline CD3+ & $75.10 \pm 1.42$ & $79.40 \pm 1.10$ & $\begin{array}{c}\text { Not } \\
\text { significant }\end{array}$ \\
\hline CD4+ & $38.95 \pm 0.70$ & $39.55 \pm 0.59$ & 0.006 \\
\hline CD8+ & $25.15 \pm 0.91$ & $22.00 \pm 0.60$ & $\begin{array}{c}\text { Not } \\
\text { significant }\end{array}$ \\
\hline CD19+ & $19.35 \pm 0.68$ & $18.70 \pm 0.69$ & 0.003 \\
\hline $\begin{array}{c}\text { CD4/CD8 } \\
\text { ratio }\end{array}$ & $1.58 \pm 0.06$ & $1.82 \pm 0.05$ & \\
\hline
\end{tabular}

\section{References:}

1. World Health Organization 2006. Brucellosis in humans and animals. WHO Library Cataloguing-inPublication Data. Jahans, K. L., Foster G. and Broughton E. S. 1997.

2. The characterization of Brucella strains isolated from marine mammals. Vet. Microbiol., 57: 373-382.

3. Jacob, N. R., Rodríguez, C. G., Binaghi, M. A., Scapellato, P. G., Rosales Ostriz, M. B., Ayala, S. M. and Lucero, N. E. 2008. Brucellosis complicating chronic non-infectious disorders: diagnostic and therapeutic dilemmas. J. Med. Microbiol., 57: 1161-1166.

4. Ocon, P., Reguera, J. M., Morata, P., Juarez, C., Alonso, A, and Colmenero, J. D. 1994. Phagocytic cell function in active brucellosis. Infect. Immun., 62: 910-914.

5. Ko, K. and Splitter, G. 2003. Molecular host-pathogen interaction in brucellosis: current understanding and future approaches to vaccine development for mice and humans. Clin. Microbiol. Rev., 1: 65-78.

6. Celik, I. and Akbulut, H. H. 2005. Lymphocyte subpopulations in patients with acute brucellosis. Turk. J. Med. Sci., 35: 235-239.

7. Traherne, J. A. 2008. Human MHC architecture and evolution: implications for disease association studies. Int. J. Immunogenet., 35: 179-192.

8. Bravo, M. J., Colmenero, J. D., Alonso, A. and Caballero A. 2003. HLA-B*39 allele confers susceptibility to osteoarticular complications in human brucellosis. J. Rheumatol., 30:1051-1053.

9. Ertem, G. T., Tanyel, E., Tulek, N., Ulkar, G. B. and Doganci, L. 2004. Osteoarticular involvement of brucellosis and HLA-B27 antigen frequency in Turkish patients. Diagn. Microbiol. Infect. Dis., 48: 243-245.

10. Alavi, S. M., Seraj, M. S., Etemadi, A, and Moradzadegan H. 2009. Frequency of HLA-B27 antigen in Iranian patients with brucellosis and its relationship with osteoarticular complication. Pak. J. Med. Sci., 25: 253-256.

11. Ad'hiah, A. H. 1990. Immunogenetic Studies in Selected 
Human Diseases. Ph.D. Thesis, University of Newcastle upon Tyne, England.

12. Burgner, D., Jamieson, S. E. and Blackwell, J. M. 2006. Genetic susceptibility to infectious diseases: big is beautiful, but will bigger be even better? Lancet Infect. Dis., 6: 653-663.

13. Murphy, E., Robertson, G. T., Parent, M., Hagius, S.D., Roop R. M., Elzer, P. H. and Baldwin, C. L. 2002. Major histocompatibility complex class I and II expression on macrophages containing a virulent strain of Brucella abortus measured using green fuorescent protein-expressing brucellae and fow cytometry. FEMS Immunol. Med. Microbiol., 33: 191-200.

14. Yingst, S. and Hoover, D. L. 2003. $\mathrm{T}$ cell immunity to brucellosis. Crit. Rev. Microbiol., 29: 313-331.

15. Forestier, C., Moreno, F., Méresse, S., Phalipon, A., Olive, D., Sansonetti, P. and Gorvel1, J-P 1999. Interaction of Brucella abortus lipopolysaccharide with major histocompatibility complex class II molecules in B lymphocytes. Infect. Immun., 67: 4048-4054.

16. Pareja, E., Bonal, F. J., Paule, P., Salvatierra, D. and Garrido, F. 1985. HLA antigens in brucellosis. Exp. Clin. Immunogenet., 2: 1-3.
17. Al-Rawi, Z. S., Al-Khateeb, N. and Khalifa, S. J. 1987. Brucella arthritis among Iraqi patients. Br. J. Rheumatol., 26: 24-27.

18. Araya, L. M., Elzer, P. H. and Rowe, G. E. 1989. Temporal development of protective cellmediated and humoral immunity in $\mathrm{BALB} / \mathrm{c}$ mice infected with Brucella abortus. J. Immunol., 143: 3330-3337.

19. Oliveira, S. C. and Splitter, G. A. 1995. CD8+ type 1 CD44h $i$ CD45 $\mathrm{RB}^{10} \mathrm{~T}$ lymphocytes control intracellular Brucella abortus infection as demonstrated in major histocompatibility complex class Iand class II-deficient mice. Eur. J. Immunol., 25: 2551-2557.

20. Moreno-Lafont M. C., LopezSantiago R. and Paredes-Cervantes V. 2003. Activation and proliferation of $\mathrm{T}$ lymphocyte subpopulations in patients with brucellosis. Arch. Med. Res., 34: 184-193.

21. Gazapo, E., Gonzalez Lahoz, J. and Subiza, J. L. 1990. Lymphocyte subpopulations in the evolution of brucellosis. Rev. Clin. Esp., 186: 369-373.

22. Ad'hiah, A. H. 2009. Distribution of HLA polymorphism in a sample of Iraqi Arabs in comparison with three Arab Gulf populations. Iraqi Journal of Science (Accepted). 
تكرار مستضدات خلايا الدم البيض البشرية لعينة عراقية من مرضى داء البروسيلا آمنتة نصيف جاسمث****

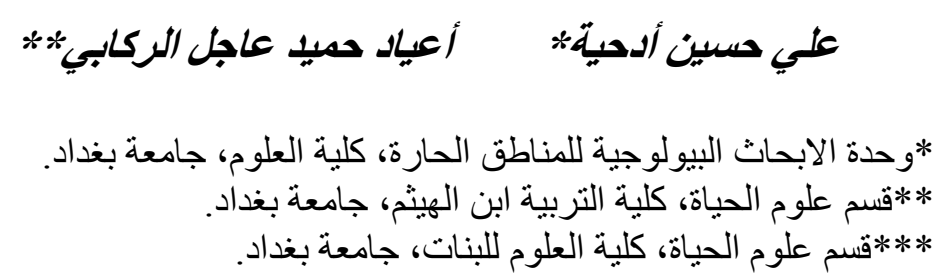

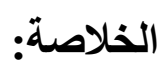

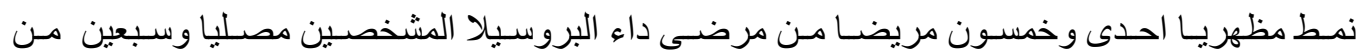

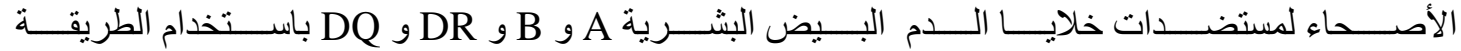

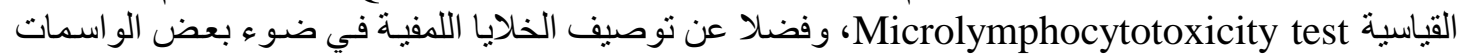
(CD19 و CD8 CD4 , CD3)

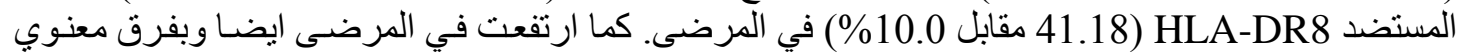

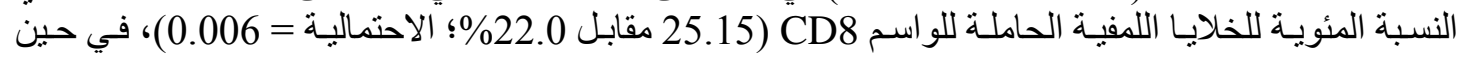
انخفضت معنويا الخلايا الحاملة للواسم CD3 (75.1 مقابل 79.4\%؛ الاحتمالية = 0.02). 